\title{
Whether There Is a Competition between the Interprovincial Governments on Fiscal Expenditure
}

\section{-From the Detection of Spatial Correlation}

\author{
Yuanyuan Wang \\ Beijing Normal University, Beijing, China \\ Email: wangyuanyuan0816@163.com
}

How to cite this paper: Wang, Y.Y. (2018) Whether There Is a Competition between the Interprovincial Governments on Fiscal Expenditure. Open Journal of Business and Management, 6, 454-461.

https://doi.org/10.4236/ojbm.2018.62033

Received: March 19, 2018

Accepted: April 27, 2018

Published: April 30, 2018

Copyright $\odot 2018$ by author and Scientific Research Publishing Inc.

This work is licensed under the Creative

Commons Attribution International

License (CC BY 4.0).

http://creativecommons.org/licenses/by/4.0/

\begin{abstract}
The fiscal decentralization gives the local government economic participation status. Is there a spatial spillover effect in the process of local government financial expenditure? This paper introduces the spatial econometric model, and applies the 2005-2016 data to test the spatial correlation of the whole country by calculating the Moran's I index and the Geary index C. At the same time, we use the local Moran's index to detect the degree of agglomeration between regions. The results show that there is a significant spatial spillover effect between regions. There are policy imitation behaviors in the region and adjacent areas, and there is a high value and high value agglomeration among regions, as well as a trend of low value and low value agglomeration.
\end{abstract}

\section{Keywords}

Government, Expenditure Competition, Moran's I Index, Geary Index C

\section{Introduction}

Whether there is a competition between Chinese governments on fiscal expenditure? Tax competition has always been the main means of fiscal competition, but with the change of society and the development of time, the preferential tax policy has shifted from region to industry, and the means of local fiscal competition have gradually shifted to the field of expenditure competition, which provides public goods and services [1]. Different scholars have chosen different methods to verify the existence of financial expenditure competition and test the effects of financial expenditure competition. The research on spatial interaction 
behavior of fiscal expenditure strategy which applies spatial econometric model regards that the expenditure of economic construction and maintenance expenditure is not conducive to the growth of economic construction and social expenditure competition has positive effect on economic growth [2]. There exists "horizontal strategic interaction" among local government and "vertical common reflect" among central and local governments in the field of fiscal expenditure [3]. Fiscal expenditure competition can cause factor flow. However the viewpoints of the effect of fiscal expenditure competition among scholars are not quite the same. Some believe that the basic economic construction expenditure can have suppressive effect on economic growth, and have positive effect on science and education [4]. Fiscal expenditure competition distorts the structure of fiscal expenditure, leading to the low level of public service expenditure [5]. Therefore scholars make further research on the effect of fiscal expenditure competition on provincial capital flows and consider that in the field of social and livelihood, fiscal expenditure competition can have an effect on capital inflows [6]. Some scholars further detect the invalidity of fiscal expenditure competition that there is $U$ linear relationship between fiscal expenditure competition and economic growth and excessive competition is not favorable for economic growth.

\section{General Introduction of Fiscal Expenditure Structure}

The financial expenditure is divided into four categories, public management expenditure, science and education expenditure, social security expenditure and economic construction expenditure. In case of the annual population differences and in order to reflect the reality of the situation, per capital level to reflect fiscal expenditure situation is applied.

From Figure 1 above, there are four shades from deep to shallow, representing public management expenditure, economic construction expenditure, social security expenditure and the science and education expenditure respectively. The entire circle represents the whole local fiscal expenditure and each part represents the proportion of fiscal expenditure. The 12 figures represent the structure order of fiscal expenditure from 2005 to 2016 respectively; dynamic changes can be seen while observing 12 figures continuously.

As shown in Figure 2, as time goes on, the proportion of per capita public management expenditure is gradually reduced, from $36 \%$ in 2005 to $14 \%$ in 2016 $\mathrm{m}$ while the proportion of per capita economic construction expenditure shows a gradually rise, from $31 \%$ in 2005 to $41 \%$ in 2016 . Science and education expenditure contribute the largest proportion of $42 \%$ in 2006, while the rest years are maintained at around $27 \%$. The social security expenditure proportion has been maintained at $15 \%$. Considering this, we can see that with the development of society, the fiscal expenditure structure with the largest proportion of economic construction, public management expenditure and the lowest social security expenditure has been gradually formed. The structure of fiscal expenditure is biased towards economic construction expenditure. 


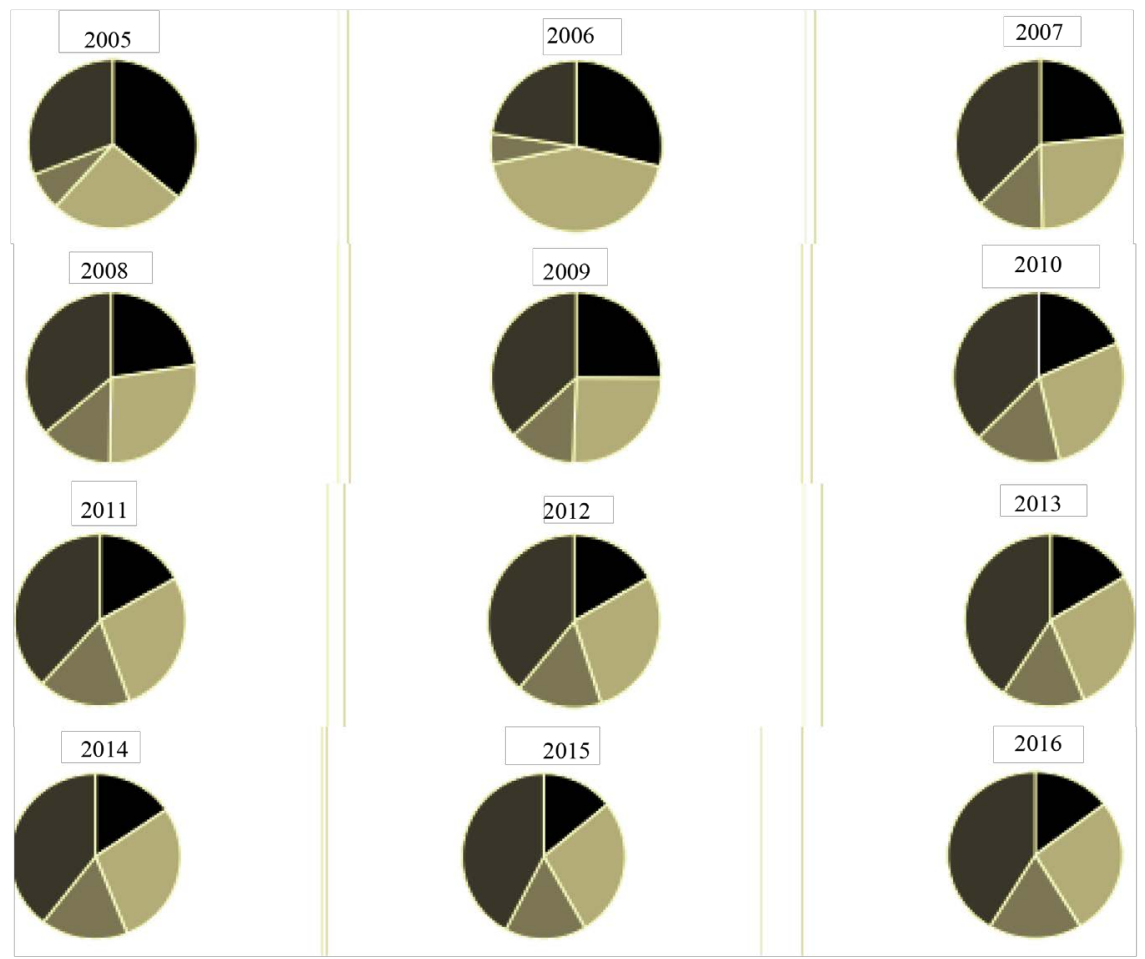

Figure 1. The proportion of all kinds of financial expenditure.

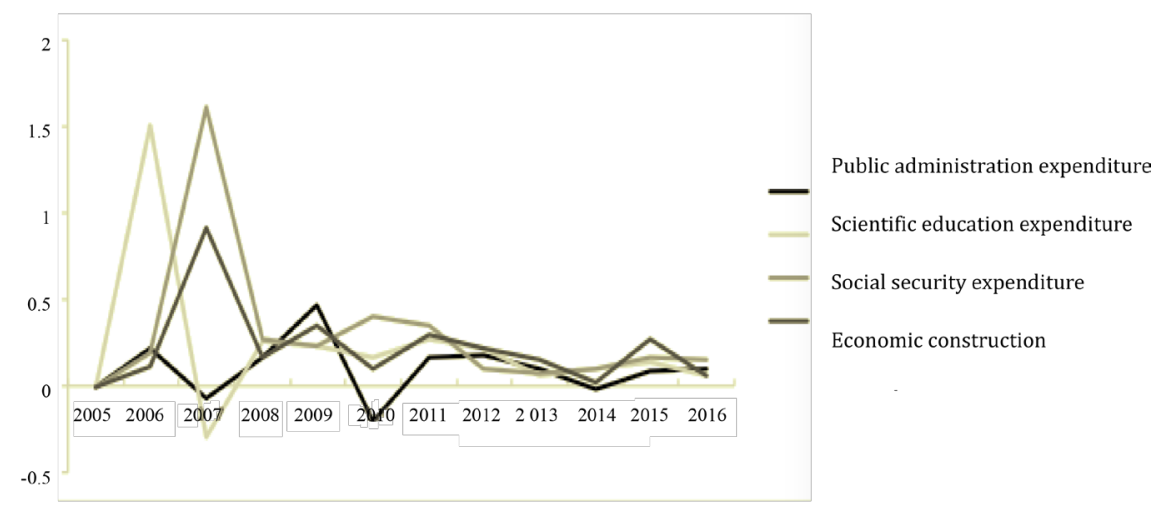

Figure 2. Growth rate of various kinds of financial expenditure.

Figure 2 above are four kinds of per capita fiscal expenditure growth rate, four shades from deep to shallow, representing the public management expenditure, economic construction expenditure, social security expenditure and science and education expenditure. As shown in figure, four kinds of fiscal expenditure structures show a fluctuation forward in growth trend. Before 2010, all kinds of fiscal expenditure growth rate show a big fluctuation, and different categories of financial expenditure show a large growth, among which the social security expenditure and science and education expenditure violate the great. However, the growth rate of fiscal expenditure has been maintained at a certain level since 2010, and the difference in the growth rate of different categories of fiscal expenditure is not significant, the reason as follow. 
It might be due to the acceleration of urban-rural integration process in 2008, breaking the previous discussion in the theoretical stage. The reform of China starts in the rural area, but peaks in cities; the way of prosperity after the first half is not suitable to the reality of urban and rural development. Originally hoping to promote the development of rural areas by urban development, but the reality is that the division of urban and rural and backward rural areas gradually becomes obstacles to the further development of the city. A trickledown effect on the backward areas in developed areas has changed into the consumption on kinds of rural resources. In view of this, the central government rethinks the development mode of urban and rural areas, implements the rural reform centered on the countryside, and passively forces the initiative for farmers, and speeds up the process of urban-rural integration. As a result, the growth of fiscal expenditure has changed accordingly.

\section{Spatial Correlation Standard}

There are a lot of spatial correlation standard, Moran index method, Gil coefficient method, local Moran index method, local Gil coefficient method, LM test, LR test, among which the Moran index method, Gil coefficient method can observe the correlation between variables from the whole; local Moran index, local Gil coefficient can gather the detection area; LM test and LR test can further test errors such as the existence of spatial correlation. The research purpose of this part is to test whether there is spatial dependence and fiscal competition among local governments, therefore Moran index, Gil coefficient and local Moran index research are selected.

The Moran's I index is the first method to be applied to the global cluster test (Cliff and Ord, 1973). It shows that the adjacent areas in the whole study area are similar, different (spatial correlation and negative correlation) are still independent. Moran's I index calculation formula is as follows: $\bar{X}$

$$
I=\frac{n \sum_{i=1}^{n} \sum_{j=1}^{n} w_{i j}\left(x_{i}-\bar{x}\right)}{\sum_{i=1}^{n} \sum_{j=1}^{n} w_{i j}\left(x_{i}-\bar{x}\right)^{2}}=\frac{n \sum_{i=1}^{n} \sum_{j \neq 1}^{n} w_{i j}\left(x_{i}-\bar{x}\right)\left(x_{i}-\bar{x}\right)}{S^{2} \sum_{i=1}^{n} \sum_{j=1}^{n} w_{i j}}
$$

The $n$ is the total number of regions in the study; $W_{i j}$ is the spatial weight of the area $I$ and the area $J$ is the adjacent area, which is divided into geographical proximity and economic neighbor. So $W_{i j}$ is divided into geographical weight and economic weight. $X_{i}$ and $X_{J}$ are the observation variables of region $I$ and region $J$ respectively, which are the financial expenditure items. $X$ is the average attribute observation variable and $S^{2}$ is the variance of observed variables.

The range of Moran's I index is generally between -1 to 1 ; more than 0 says positive correlation; value close to 1 represents that similar values bond together and less than 0 indicates negative correlation values, close to -1 indicates different attributes bond together. If close to 0 , then there is no spatial autocorrelation, no spatial dependence, and no expenditure competition.

A Geary index $C$ is also an index of global clustering tests. A median deviation 
of the product is used in calculation of Moran's I index, but the Geary index $C$ accounts the deviation between the values. The calculation formula is as follows:

$$
C=\frac{(n-1) \sum_{i=1}^{n} \sum_{j=1}^{n} w_{i j}\left(x_{i}-x_{j}\right)^{2}}{2 \sum_{i=1}^{n} \sum_{j=1}^{n} w_{i j} \sum_{i=1}^{n}\left(x_{i}-x_{j}\right)^{2}}
$$

The value of Geary index $C$ is generally between 0 and 2 (2 is not a strict upper bound), greater than 1 is a negative correlation, equal to 1 , indicating no correlation, and less than 1 indicates a positive correlation, contrary to the Moran's I index.

The local Moran's I (Anselin, 1995) is used to check whether there are similar or different observation values in the local area. The local Morlan index of area I is used to measure the correlation degree between the area I and its adjacent regions. The calculation formula is as follows:

If I is greater than 0 , it represents a high value-high value, low value-low value cluster; and if the I is less than 0 , the low value-high value, high value-low value cluster is expressed.

\section{Spatial Correlation Test}

\subsection{Data Selection}

The article from 2004 to 2016 the provincial dynamic panel data to study from 2005 to 2004 as the base, the relevant financial data in 2016, the main source of "China Statistical Yearbook" and the "statistical yearbook". Because Chongqing was divided into municipalities in 1997, for the sake of uniformity of the caliber and the length of the dynamic panel data, the last 12 years were selected as the year of analysis.

\subsection{Analysis of the Results of Detection Section}

\subsubsection{Moran Index and Gil Coefficient Detection}

Table 1 below is the result of spatial correlation test of national fiscal expenditure in 2016. According to the results, in general, from 2005 to 2016, fiscal expenditure spatial correlation index has significant correlation, indicating the existence of spatial dependence of fiscal expenditure in adjacent areas with competition. Specifically, the paper selects two matrixes of geographical weight and economic weight to calculate the spatial dependence of geographically spaced adjacent areas and similar economic regions. Comparing Moran index,

Table 1. Moran's I index and Geary's C index test result.

\begin{tabular}{|c|c|c|c|c|c|c|c|c|c|c|c|c|c|}
\hline eight & & 2005 & 2006 & 2007 & 2008 & 2009 & 2010 & 2011 & 2012 & 2013 & 2014 & 2015 & 2016 \\
\hline & Moran's I & $0.122^{\star}$ & $0.15^{\star *}$ & $0.138^{\star}$ & $0.147^{\star}$ & $0.169^{\star *}$ & $0.21^{* *}$ & $0.192^{\star *}$ & $0.202^{\star *}$ & $0.209^{\star *}$ & $0.199^{\star *}$ & $0.175^{\star *}$ & $0.161^{\star *}$ \\
\hline & Moran's I & $0.548^{\star * \star}$ & $0.574^{\star * *}$ & $0.523^{* * *}$ & $0.42^{* * *}$ & $0.36^{\star * *}$ & $0.252^{\star * *}$ & $0.169^{* *}$ & $0.118^{*}$ & $0.121^{\star}$ & $0.11^{\star}$ & $0.171^{\star *}$ & $0.191^{\star *}$ \\
\hline Economic & Geary's C & $0.45^{\star * *}$ & $0.428^{\star * *}$ & $0.463^{* * *}$ & $0.54^{* * *}$ & $0.587^{\star * *}$ & $0.684^{* * *}$ & $0.745^{\star *}$ & $0.784^{*}$ & $0.773^{*}$ & $0.775^{\star}$ & $0.729^{* *}$ & $0.706^{\star *}$ \\
\hline
\end{tabular}


Moran index of economic weight is more significant than the geographical weight of Moran index, especially in 2005, 2006, 2007 and 2010. The index is more than 0 and close to $1, \mathrm{P}$ values are less than 0.01 which strongly rejects the null hypothesis, therefore, among the total fiscal expenditure competition, economic space correlation strategy behavior contributes a larger impact on the region. The region selects strategy imitation. Considering Geary s C index, from 2005 to 2016, there is significance, but economic spatial similar regions is more significant than the geographically adjacent areas, indicating that in the total financial expenditure competition, the area is more affected by economic spatial area. The index is less than 1 , indicating that there is a significant positive correlation in similar regions. The strategic mimic behavior is selected in the area whose result is consistent with the Moran index.

\subsubsection{Local Moran's I Index Detection}

Figure 3 are local Moran's I index plot of 31 provinces from 2005 to 2016. According to the test results, most of the local governments are in the third quadrant, namely low value-low value type, indicating that there exists strong dependence among adjacent areas, and there is fiscal expenditure behavior. In the figures above, Beijing, Tianjin, Qinghai, Ningxia and Tibet are all in the first quadrant. The first quadrant is high-high value type, indicating that the five local fiscal expenditures are higher than that of other places; the surrounding areas have gathered a higher amount of fiscal expenditure. Beijing and Tianjin
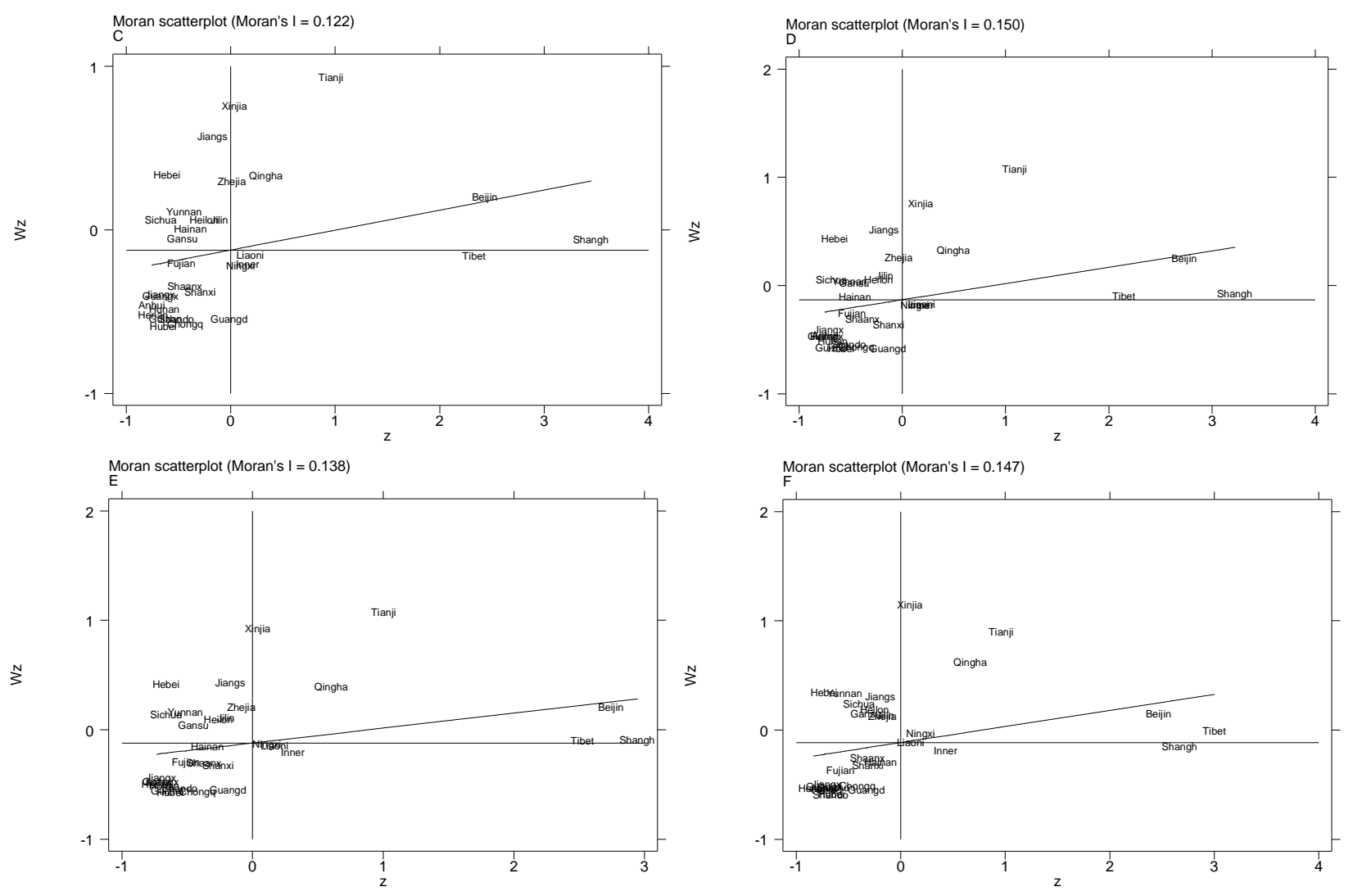

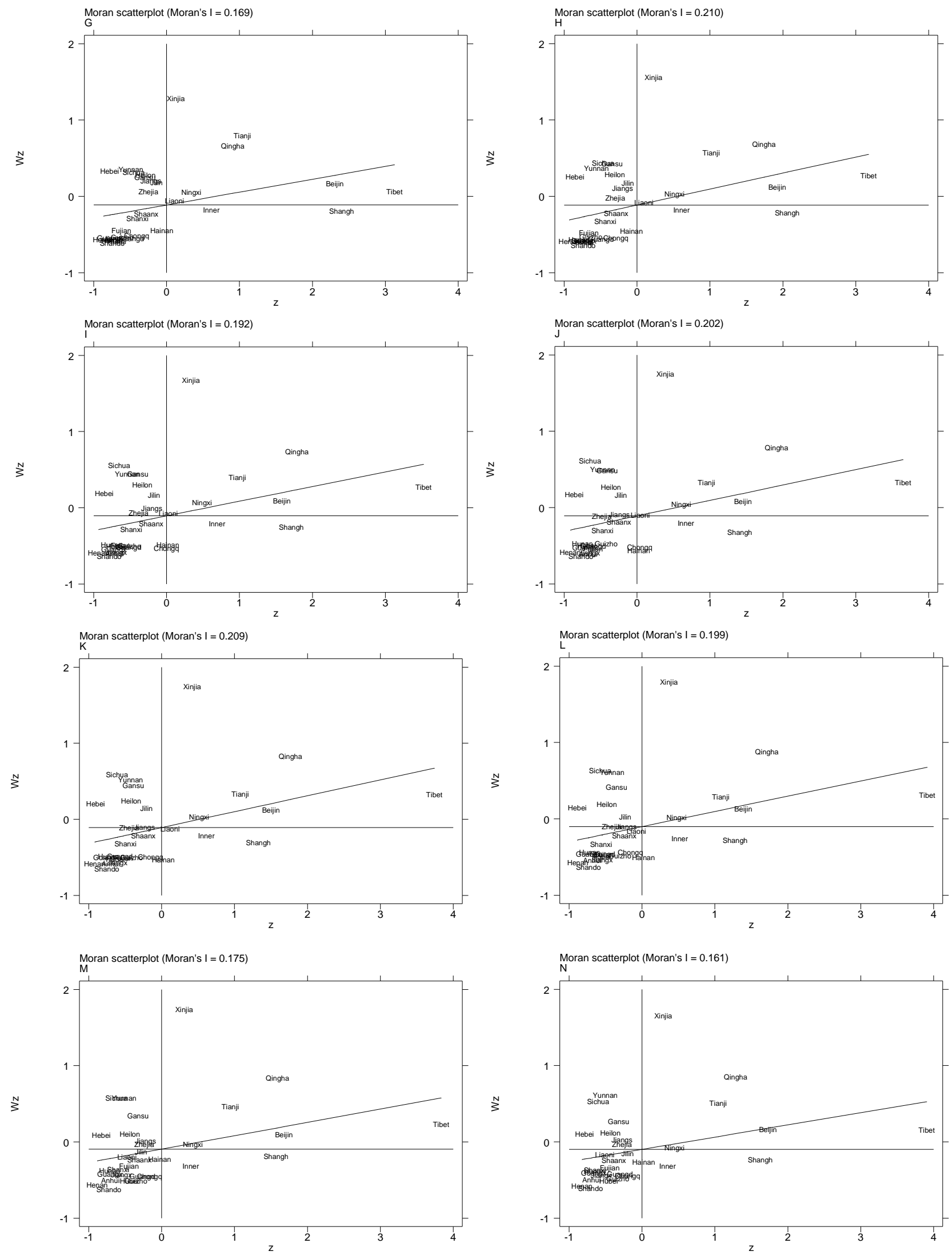

Figure 3. Local Moran's I index test results. 
are geographically adjacent areas; Qinghai, Ningxia, and Tibet also belong to the adjacent geographical place. However Beijing and Tianjin belong to the Beijing-Tianjin-Hebei economic developed areas, while Qinghai, Ningxia and Tibet are economically backward areas. These five areas are similar in total fiscal expenditure, indicating that the central government tries to achieve the equalization of the public level of service through the transfer payment for Qinghai, Ningxia and Tibet. It also can be seen in these three places, besides central government related preferential, similar fiscal competition strategies are utilized. The fourth quadrant is high value-low value type, including Shanghai and Inner Mongolia, indicating the existence of spatial heterogeneity in the two regions. Most provinces and cities are located in third quadrant, low value-low value provinces and cities, including Eastern, central and western regions. The fourth part includes Jilin, Gansu, Heilongjiang and Sichuan.

\section{Conclusion}

The calculation of Moran index, Gil index and local Moran index can draw the conclusion that the total fiscal expenditure of 31 provinces in China has strong spatial dependence, which is not only affected by the geographically adjacent area, but also affected by the economically adjacent area, and the fiscal expenditure behavior is competitive.

\section{References}

[1] Li, Y. and Shen, K. (2008) Regional Characteristics of Inter District Competition, Strategic Fiscal Policy and FDI Growth Performance. Economic Research, No. 5, 58-69.

[2] Guo, Q. and Jia, J. (2009) Strategic Interaction between Local Governments, Fiscal Expenditure Competition and Regional Economic Growth. Manage the World, No. $10,17-27+187$

[3] Wang, M., Lin, J. and Yu, Z. (2010) The Characteristics of Chinese Local Government Financial Competition Behavior: Whether "Brother Competition" and "Father Son Dispute" Coexist? Manage the World, No. 3, 22-31 + 187-188.

[4] Lin, J. (2011) The Economic Growth Effect of Local Government Financial Competition in China. Economic Management, 33, 10-15.

[5] Lv, W. and Zheng, S. (2012) Does Fiscal Competition Distort the Structure of Local Government Expenditure?-An Empirical Test Based on the Provincial Panel Data in China. Financial Research, No. 5, 36-40.

[6] Zhang, L. and Yang, J. (2017) How the Local Government Financial Competitive Behavior Affects the Inter Provincial Capital Flow. Contemporary Finance \& Economics, No. 5, 24-33. 